DOI: 10.12731/2658-6649-2019-11-5-2-100-105

УДК 616.1:616-003,96-053.7(571.513)

\title{
ФУНКЦИОНАЛЬНЫЕ \\ ОСОБЕННОСТИ АДАПТАЦИИ У ЮНОШЕЙ АБОРИГЕНОВ ХАКАСИИ
}

Петров И.А., Пуликов А.С., Маркович Е.Б.

Обследовано 137 юнотей-хакасов антропометрическими и физиологическими методиками на определение состояния динамического соответствия и равновесия между живой системой и внешней средой. Установлено, что юноши с астеническим типом конституции имеют более высокий уровень резервов сердечно-сосудистой системы, выносливости и лучше адаптированы к условиям окружающей среды, чем юноши-нормостеники и пикники.

Вне зависимости от конституции юноши-хакасы в большей половине случаев испытывают напряжение в работе сердечно-сосудистой системы по показателю КЭК.

Ключевые слова: адаптация; выносливость; энергопотенцииал; юноши- аборигень;; Республика Хакасия.

\section{FUNCTIONAL FEATURES OF THE ADAPTATION IN YOUNG ABORIGENS OF KHAKASSIA}

\author{
Petrov I.A., Pulikov A.S., Markovich E.B.
}

137 young Khakass boys were examined by anthropometric and physiological methods to determine the state of dynamic correspondence and balance between the living system and the environment. It is established that young men with asthenic type of Constitution have a higher level of reserves of the cardiovascular system, endurance, and better adapted to the environmental conditions than boys normostenik and picnics. Regardless of the Constitution, Khakass boys in more than half of cases experience stress in the work of the cardiovascular system in terms of KAC.

Keywords: adaptation; endurance; energy potential; young men-aborenees; The Republic of Khakassia. 


\section{Введение}

Адаптация к кругу факторов внешней и внутренней среды является актуальной современной проблемой, требующей широкого круга внимания специалистов $[1,2]$. Согласно данным предыдущих исследователей, большое значение придается связям между адаптацией и физическим развитием, психическими и физическим нагрузками, утомлением и здоровьем $[3,4]$.

На современном этапе исследований процесс адаптации к условиям среды изучается с обязательным использованием интегративных психофизиологических подходов, позволяющих сформировать целостное понимание происходящих в развивающемся организме молодых людей изменениях [2].

\section{Материалы и методы исследования}

К исследованию на добровольной основе были привлечены 137 лиц юношеского возраста коренного (монголоидного) населения Республики Хакасия (РХ) стандартными антропометрическими и физиологическими методиками.

База данных создавалась из абсолютных и относительных показателей, расчетных коэффициентов и индексов: длина и масса тела, ЧДД - частота дыхательных движений в 1 мин, индекс Робинсона (ИР), коэффициент экономизации кровообращения (КЭК), коэффициент выносливости (КВ), показатели уровней адаптационного потенциала по Р.М. Баевскому [5]: АП=0,011 х ЧСС + 0,014 х АДс $+0,008 \times$ АДд + 0,014 х КВ + 0,009 х МТ - 0,009 x Р-0,27, где: ЧСС - частота сердечных сокращений (уд./мин); АДс - артериальное давление систолическое (мм.рт.ст); АДд - артериальное давление диастолическое (мм.рт.ст); КВ - календарный возраст (годы); МТ - масса тела (кг); Р - рост (см).

Статистическая обработка результатов проводилась с помощью пакета программ STATISTICA FOR WINDOWS (VERSION 10.0) и «MS Exel 2007» с предоставлением средних статистических значений, медианы $(\mathrm{Me})$, интерквартильного интервала $\left(\mathrm{Q}_{1}-\mathrm{Q}_{3}\right)$ и достоверной значимости отличий $(\mathrm{p})$.

\section{Результаты исследования}

Средняя длина тела у юношей коренного населения РX равна $172,38 \pm 0,73$ см и варьировала от 142,9 см до 192,9 см. Масса тела $64,43 \pm 1,19$ кг при полученных максимальных $(98,4$ кг) и минимальных $(47,9$ кг) значениях. 
АДс в покое составляла $128 \pm 2,2$ мм.рт.ст., АДд - 72士 1,1 мм.рт.ст., ЧДД - 20,1 $\pm 0,6$ в 1 мин, ЧСС - 77,2 $\pm 1,64$ уд/мин.

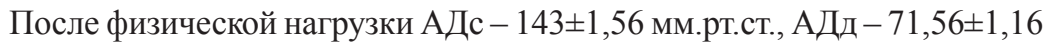
мм.рт.ст., ЧДД $-26 \pm 3,4$ в 1 мин, ЧСС находилась в пределах $101,9 \pm 1,2$ уд/мин.

Оценка резервов сердечно-сосудистой системы показала, что $8,1 \%$ юношей с ИР $=59,1$ имеют отличный уровень резервов ССС, $11,6 \%$ с ИР $=76,17\left(\mathrm{Q}_{1-3} 74,1-77,57\right)-$ хороший уровень, 23,3 \% юношей с ИР=91,0 $\left(\mathrm{Q}_{1-3} 89,4-93,1\right)$ - средний уровень энергопотенциала. Плохой и очень плохой уровни функциональных возможностей с нарушением вегетативной регуляции деятельности ССС $\left(\mathrm{p}_{1-2}=0,002, \mathrm{p}_{1-3}=0,0004, \mathrm{p}_{2-3}=0,001\right)$ имели $56,9 \%$ юношей.

Коэффициент экономизации кровообращения (КЭК), отражающий выброс крови за 1 минуту, оказался распределенным среди юношей следующим образом: $10,1 \%$ от общего количества юношей были с КЭК=2249 $\left(\mathrm{Q}_{1-3} 2062-2476\right)$, а 90,0\% имели КЭК=4602 $\left(\mathrm{Q}_{1-3} 3659-5461\right)\left(\mathrm{p}_{1-2}=0,002\right)$. Величины КЭК свыше 2600 ед. свидетельствуют о напряженном режиме работы сердечно-сосудистой системы.

По коэффициенту выносливости (КВ) у юношей-хакасов $32,9 \%$ астеников, $46,5 \%$ нормостеников и $38,7 \%$ пикников выявлено оптимальное состояние CCC (Me1=13,4; $\left.\mathrm{Q}_{1-3}=12,7-14,1\right)$. У 37,0\% астеников, 23,8\%- нормостеников и $31,9 \%$ пикников определено ослабление функции ССС (Me2=20,34; $\left.\mathrm{Q}_{1-3}=17,3-20,9\right)$. У $30,0 \%$ астеников, 29,6\% нормостеников и $28,4 \%$ пикников от общего количества обследованных юношей отмечено утомление, как более тяжелое состояние деятельности ССС (Ме3=9,5; $\left.\mathrm{Q}_{1-3}=8,3-10,4\right)$.

В целом при исследовании адаптационного потенциала установлено, что юноши астенического типа телосложения более адаптированы и имеют в $40 \%$ случаев удовлетворительную адаптацию, а нормостеники и пикники только в $32 \%$ и $7 \%$ случаев.

\section{Выводы}

1. Адаптация с параллельной направленностью адаптационных процессов и разной степенью их выраженности характерна для юношей-аборигенов разного типа телосложения, проживающих в одинаковых социально-экологических условиях.

2. По отношению к юношам нормостеникам и пикникам юноши с астеническим типом конституции лучше адаптированы к условиям окружающей среды. 
3. В большей половине случаев юноши-хакасы испытывают напряжение в работе сердечно-сосудистой системы по показателю КЭК и имеют плохой уровень резервов сердечно-сосудистой системы вне зависимости от конституции.

\section{Список литературы}

1. Пуликов А.С., Москаленко О.Л. Взаимосвязь физического развития и полового диморфизма с адаптационными возможностями юношей // Современные исследования социальных проблем (электронный научный журнал). 2012. №1. С. 1158-1168.

2. Корельская И.Е., Блохина Н.В. Адаптация к обучению в университете в зависимости от типа вегетативной нервной системы студентов// Успехи современного естествознания. 2015. №9 (3). С. 503-6.

3. Михайлова Л.А. Мальцева Е.А. Гемодинамичекие показатели здоровых лиц юношеского возраста с различным типом вегетативной реактивности // Сибирское медицинское обозрение.2012. №1 (73). С. 46-50.

4. Пуликов А.С., Москаленко О.Л. Динамика массы и плотности тела в зависимости от конституции, полового диморфизма и возраста юношей в условиях городского антропотехногенного загрязнения // Международный журнал прикладных и фундаментальных исследований. 2014. №8-3. C. $77-80$.

5. Баевский Р.М. Оценка и классификация уровней здоровья с точки зрения теории адаптации.// Вестник академии медицинских наук СССР. 1989. (8). 73.

\section{References}

1. Pulikov A.S., Moskalenko O.L. Vzaimosvyaz fizicheskogo razvitiya i polovogo dimorfizma s adaptatsionnymi vozmozhnostyami yunoshey [The relationship of physical development and sexual dimorphism with the adaptive capabilities of young men]. Sovremennyye issledovaniya sotsialnykh problem [Contemporary research on social problems]. 2012. №1, pp. 1158-1168.

2. Korelskaya I.E., Blokhina N.V. Adaptatsiya k obucheniyu v universitete v zavisimosti ot tipa vegetativnoy nervnoy sistemy studentov [Adaptation to study at the university, depending on the type of the autonomic nervous system of students]. Uspekhi sovremennogo estestvoznaniya [Successes of modern science]. 2015. №9 (3), pp. 503-6.

3. Mikhaylova L.A., Maltseva E.A. Gemodinamichekiye pokazateli zdorovykh lits yunosheskogo vozrasta s razlichnym tipom vegetativnoy reaktivnosti [Hemodynamic indicators of healthy persons in adolescence with a different type of 
autonomic reactivity]. Sibirskoye meditsinskoye obozreniye [Siberian Medical Review]. 2012. №1 (73), pp. 46-50.

4. Pulikov A.S., Moskalenko O.L. Dinamika massy i plotnosti tela v zavisimosti ot konstitutsii. polovogo dimorfizma i vozrasta yunoshey v usloviyakh gorodskogo antropotekhnogennogo zagryazneniya [Dynamics of body mass and density depending on the constitution, sexual dimorphism and the age of young men in the conditions of urban anthropotechnogenic pollution]. Mezhdunarodnyy zhurnal prikladnykh i fundamentalnykh issledovaniy [International Journal of Applied and Fundamental Research]. 2014. №8-3, pp. $77-80$.

5. Bayevskiy R.M. Otsenka i klassifikatsiya urovney zdorovia s tochki zreniya teorii adaptatsii [Evaluation and classification of health levels from the point of view of the theory of adaptation]. Vestnik akademii meditsinskikh nauk SSSR [Academy of Medical Sciences of the USSR]. 1989, (8), p. 73.

\section{ДАННЫЕ ОБ АВТОРАХ}

Петров Иван Анатольевич, студент 4 курса специальности “Лечебное дело" Медико-психолого-социального института ФГБОУ ВО Хакасский государственный университет им. Н.Ф. Катанова

Хакасская, 68, г. Абакан, 655017, Российская Федеращия ivan1997344@mail.ru

Пуликов Анатолий Степанович, главный научный сотрудник, д.м.н., профессор

Научно-исследовательский институт медицинских проблем Севера ФИЦ КНЦ СО РАН

Партизана Железняка, 32, Красноярск, 660022, Российская Федерачия

Pulik_off@mail.ru

ORCID: 0000-0002-8751-5861

Маркович Евгения Борисовна, техник директората Медико-психологосоциального института ФГБОУ ВО Хакасский государственньй университет им. Н.Ф. Катанова

Хакасская, 68, г. Абакан, 655017, Российская Федераџия echiumvul@mail.ru 


\section{DATA ABOUT THE AUTHORS}

Petrov Ivan Anatolyevich, 4th year student of the specialty "General Medicine" of the Medical-Psychological-Social Institute

Khakas State University

68, Khakasskaya Str., Abakan, 655017, Russian Federation

ivan1997344@mail.ru

ORCID: 0000-0003-2590-9467

Pulikov Anatoliy Stepanovich, chief researcher, professor

Scientific Research Institute for Medical Problems of the North FRC KSC SB RAS

3g, Partizan Zheleznyak str., Krasnoyarsk, 660022, Russian Federation Pulik_off@mail.ru

ORCID: 0000-0002-8751-5861

Markovich Evgeniya Borisovna, director's assistant of the Medical-psychological-social Institute

Khakas State University

68, Khakasskaya Str., Abakan, 655017, Russian Federation

echiumvul@mail.ru 